\title{
CLINICAL AND DEMOGRAPHIC PREDICTORS OF CONVERSION TO DEMENTIA IN MEXICAN ELDERLY WITH MILD COGNITIVE IMPAIRMENT
}

\author{
Sara G. Aguilar-Navarro ${ }^{*}$, Alberto J. Mimenza-Alvarado ${ }^{1}$, José Alberto Ávila-Funes ${ }^{1}$, \\ Teresa Juárez-Cedillo ${ }^{2}$, Carolina Bernal-López ${ }^{1}$ and Celia G. Hernández-Favela ${ }^{3}$ \\ ${ }^{1}$ Geriatrics Department, Instituto Nacional de Ciencias Médicas y Nutrición Salvador Zubirán, Mexico City; \\ Epidemiology and Health Services Research Unit, Area of Aging, Centro Médico Nacional Siglo XXI, Instituto Mexicano \\ del Seguro Social and Faculty of Superior Studies (FES) Zaragoza, Universidad Nacional Autónoma de México, Mexico \\ City; ${ }^{3}$ Universidad Autónoma de Coahuila, School of Medicine, Torreón Unit, Torreón Coahuila. Mexico
}

\begin{abstract}
Background: Mild cognitive impairment $(\mathrm{MCl})$ is considered a clinical stage between normal cognitive aging and dementia. The clinical course of $\mathrm{MCl}$ is heterogeneous, with a significant number of cases progressing to dementia or reverting back to normal. Objective: To determine the predictors of conversion from mild cognitive impairment to dementia among Mexican older adults. Materials and Methods: A sample of 175 persons underwent clinical and neuropsychological evaluation to establish mild cognitive impairment diagnosis. These patients were followed-up for a mean 3.5 years. Results: Mean age was 81.7 ( \pm 6.9 ) years, $57 \%$ were women, and mean education level was $9.5( \pm 6.1$ ) years. Sixty-one percent of mild cognitive impairment participants progressed to dementia. Multivariate Cox regression analysis showed that progression to dementia was associated with age (HR: 4.95; 95\% Cl: 1.96-12.46; $\mathrm{p}=0.001)$, low education level (HR: 5.81; 95\% Cl: 1.90-7.78; $\mathrm{p}<0.002$ ), history of stroke (HR: 3.92; $95 \% \mathrm{Cl}: 1.37-11.16 ; \mathrm{p}<0.012$ ) and cognitive decline (HR: $1.31 ; 95 \% \mathrm{Cl}: 1.18-1.45 ; \mathrm{p}=0.000$ ). Conclusions: Age, poor education, cognitive decline, and a history of stroke were predictors of conversion to dementia. The identification and control of modifiable risk factors could influence conversion to dementia. (REV INVES CLIN. 2017;69:33-9)
\end{abstract}

Key words: Dementia. Mexican elderly. Mild cognitive impairment. Predictors.

\section{INTRODUCTION}

Mild cognitive impairment $(\mathrm{MCl})$ is recognized as a transitional state between healthy cerebral aging and dementia. Since its inception in $1999^{1}$, the concept of $\mathrm{MCl}$ has evolved. Core clinical criteria for $\mathrm{MCl}$ include

Corresponding author:

* Sara G. Aguilar-Navarro

Department of Geriatrics

Instituto Nacional de Ciencias Médicas

y Nutrición Salvador Zubirán

Vasco de Quiroga, 15

Col. Belisario Domínguez, Sección XVI, Del. Tlalpan

C.P. 14080, Ciudad de México, México

E-mail: sgan30@hotmail.com cognitive impairment in one or more domains compared to appropriate normative data, with a suggested deficit level of 1.0-1.5 standard deviations (SD) below normative expectations. The key criteria that distinguish $\mathrm{MCl}$ from dementia are preservation of independence in functional abilities (i.e. activities of daily living [ADL] and
Received for publication: 02-10-2016

Accepted for publication: 12-01-2017 
instrumental activities of daily living [IADL]), and lack of significant impairment in social or occupational functioning. The $\mathrm{MCl}$ sub-types are sometimes defined based on the presence or absence of memory difficulties (amnestic vs. non-amnestic $\mathrm{MCl}$ ) and the number of affected cognitive domains ${ }^{2}$. It is therefore suggested that the diagnosis of $\mathrm{MCl}$ is supported by memory complaint, a mini-mental state examination (MMSE) score between 24 and 30, clinical dementia rating (CDR) of 0.5 , preserved $A D L$, and the absence of dementia criteria ${ }^{3}$. The clinical course of $\mathrm{MCl}$ is heterogeneous; it is a dynamic state where conversion to dementia is the most feared outcome.

Dementia is one of the most prevalent chronic diseases worldwide, and is considered a public health priority ${ }^{4}$. Therefore, identifying the early phases of cognitive decline is relevant to prevent future loss of autonomy associated with cognitive impairment ${ }^{5}$. Previous studies have evaluated the conversion from $\mathrm{MCl}$ to dementia, identifying factors associated with its progression, which included depression, low educational level, and cardiovascular risk factors (such as hypertension or diabetes) ${ }^{6,7}$. However, more longitudinal epidemiological studies are needed to identify other possible factors associated with the conversion to dementia in different social and cultural contexts, which could be an important diagnostic strategy with the purpose of preventing dementia. Thus, the main objective of the present study was to identify the predictors of conversion to dementia among Mexican older persons with the diagnosis of $\mathrm{MCl}$.

\section{MATERIALS AND METHODS}

\section{Participants and study design}

This historical prospective study was conducted at the memory clinic of a university affiliated third-level hospital in Mexico City; 175 outpatients aged 65 years or older with memory complaints were evaluated for $\mathrm{MCl}$ diagnosis between March 2010 and March 2013. Participants underwent a comprehensive clinical assessment including a clinical interview, cognitive tests, and cerebral imaging (see below). We excluded patients diagnosed with dementia or other concomitant neurological disorders such as structural lesions, which could affect their cognitive functions or functional status (e.g. Parkinson's disease, acute stroke, brain tumor, or normal pressure hydrocephalus).
A diagnosis of $\mathrm{MCl}$ was established according to the criteria proposed by Petersen, et al. ${ }^{8}$, which include: memory complaints, impaired memory for age and education level, preserved general cognitive function and functional status (ADL), and absence of dementia diagnosis. In addition to a clinical assessment, a brain MRI was performed (1.5 Tesla SIEMENS, sequences, $\mathrm{T} 1$, $\mathrm{T} 2$, gradient echo, $\mathrm{T} 2 *$ weighted images, T2 FLAIR; volumetric measure was not included). After baseline assessment, participants were followed up and evaluated for incident dementia during an average of 3.5 years. The institutional Research Ethics Committee approved the study and all subjects and/or their proxies signed an informed consent.

\section{Neuropsychological evaluation}

In addition to the Petersen criteria, the diagnosis of $\mathrm{MCl}$ was supported by the following tests:

- Mini-Mental State Examination (MMSE) for global cognition, with scores between 24 and $30^{\circ}$.

- Clinical Dementia Rating (CDR) severity scale for cognitive impairment $=0.5^{10}$.

- Preserved ADL: Functional status was assessed using the Katz Index for $A D L^{11}$, and the Lawton-Brody Scale for IADL ${ }^{12}$. The patient was considered dependent with $A D L$ score $<6$ points; independent for IADL with eight points and dependent with $\leq 7$ points for women and $\leq 5$ for men.

- Absence of dementia diagnosis ${ }^{13}$.

- The five-word test (FWT), measuring immediate recall, delayed five-minute recall, and total number of code words and semantic keys, is a valid test of verbal episodic memory. It is useful to discriminate dementia, especially $A D$, from isolated subjective complaints ${ }^{14}$.

- Verbal fluency test; it was considered abnormal if the participant was not able to recall a standardized number of correct words according to his/her educational level ${ }^{15}$

- A Frontal Assessment Battery (FAB) ${ }^{16}$ lower than 1.5 standard deviations.

- The clock drawing test (CDT), which has a maximum score of 10 points and is evaluated by giving one point for each qualitative or quantitative error ${ }^{17}$, was used to evaluate executive functions.

All participants were followed for an average of 3.5 years after which a reassessment of cognitive status was made. After this evaluation, they were categorized into 
two final diagnoses: dementia (or progressive $\mathrm{MCl}$ ) or sustained $\mathrm{MCl}$ (or stable $\mathrm{MCl}$ ).

\section{Dementia diagnosis}

Diagnosis of incident dementia was established by a twostep procedure: first, a neurologist performed a clinical and neurological examination; and second, a trained psychologist applied a battery of neuropsychological tests. Progression from $\mathrm{MCl}$ to dementia was established by a consensus of expert neurologists and geriatricians according to the Diagnostic and Statistical Manual of Mental Disorders fourth edition (DSM-IV-TR) criteria $^{18}$ in those subjects who performed $<2$ SD in the following neuropsychological battery: immediate list recall, the verbal fluency test, FAB total score, and the CDT result. The etiology of each case of dementia was classified according to the current diagnostic guidelines: the National Institute of Neurological Disorders and Stroke and Alzheimer's Disease and Related Disorders Association (NINDS-ADRDA) criteria for Alzheimer's disease ${ }^{19}$; Neary criteria for frontotemporal lobar degeneration diagnosis ${ }^{20}$; the NINDS/Association Internationale pour la Récherche et l'Enseignement en Neurosciences criteria for vascular dementia, and the Dementia with Lewy Bodies Consortium ${ }^{21}$. We used the NINDS-AIREN criteria for mixed dementia (Alzheimer's disease with cerebrovascular disease) $)^{22}$.

\section{Sociodemographic and clinical variables}

Age and education level (in years) were divided into three categories. Sex, marital status, and occupation were taken into account for the study design. Current smoking status was considered if participants reported having smoked in the last six months. History of alcohol consumption was defined as "moderate drinking", which in patients over 65 years consists of one drink per day for the last six months (National Institute on Alcohol Abuse and Alcoholism, American Psychiatric Association, and the World Health Organization) ${ }^{23}$.

The presence or absence of the following chronic diseases in the clinical records was registered: history of traumatic brain injury (TBI), diabetes, hypertension, hyperlipidemia, hypothyroidism, cardiovascular disease, atrial fibrillation, history of stroke, and depression. Depression symptoms were assessed using the Geriatric Depression Scale (GDS 15-item version), where a score $>5$ indicates the presence of depression symptoms ${ }^{24}$.
At baseline, the following laboratory determinations were performed: total cholesterol, triglycerides, highdensity lipoprotein (HDL), low density lipoprotein (LDL), vitamin B12, and folic acid levels. Subjects who at baseline had decompensated chronic illness or altered laboratory tests were excluded.

\section{Statistical analysis}

Variables are described using arithmetic mean and standard deviations (SD) or frequencies and proportions where appropriate. Chi-square test and Student's $t$ test (or Mann-Whitney test) were used where appropriate. Multivariate Cox regression analyses were used to identify the predictors of incident dementia (or progressive $\mathrm{MCl}$ ). Variables identified from within each domain were then considered together in a single Cox regression analysis, and statistically significant variables, associated with progressive $\mathrm{MCl}$ at $\mathrm{p}<0.05$ were retained in the final model. All statistical tests were performed at the 0.05 level and $95 \%$ confidence intervals $(\mathrm{Cl})$ were given. Statistical tests were performed using SAS software (SAS Institute Inc., Cary, NC, USA).

\section{RESULTS}

From the initial 175 patients, data from 125 were included in the final statistical analyses; 50 patients were excluded because their follow-up records were incomplete. Mean age was 81.7 years (SD: 6.9; range 65-89 years), $57 \%$ were women, and mean education years was 9.5 (SD: 6.1). Hypertension (73\%) and diabetes (38\%) were the most frequent chronic diseases.

Mean follow-up was 3.5 (SD: 2.5) years and 76/125 (61\%) participants progressed to dementia. The types of dementia were as follows: mixed dementia (59.7\%), Alzheimer's disease (19.9\%), and vascular dementia (19.5\%).

Table 1 shows the comparative analyses between progressive and non-progressive $\mathrm{MCl}$. In comparison with the non-progressive subgroup, those who progressed were older $(p<0.001)$ and had lower educational levels $(p=0.016)$. Also, they performed lower in the immediate and delayed recall test $(p<0.001)$ as well as in verbal fluency $(p=0.012)$, semantic fluency test $(p<0.001)$, and MMSE score $(p<0.001)$, compared with the non-progressive $\mathrm{MCl}$ subgroup. 
Table 1. Comparison between stable and progressive mild cognitive impairment according to sociodemographic variables, cardiovascular risk factors, and cognitive evaluation

\begin{tabular}{|c|c|c|c|c|}
\hline Variable & $\begin{array}{c}\text { All } \\
(n=125)\end{array}$ & $\begin{array}{l}\text { Stable MCl } \\
(n=49)\end{array}$ & $\begin{array}{c}\text { Progressive } \mathrm{MCl} \\
(\mathrm{n}=76)\end{array}$ & $\mathrm{p}$ value \\
\hline \multicolumn{5}{|l|}{ Age, n (\%) } \\
\hline $65-74$ years & $18(14.6)$ & $12(66.7)$ & $6(33.3)$ & \multirow[t]{3}{*}{$<0.001$} \\
\hline $75-84$ years & $55(44.7)$ & $28(50.9)$ & $27(49.1)$ & \\
\hline$\geq 85$ years & $50(40.6)$ & $9(18.0)$ & $41(82.0)$ & \\
\hline Women, n (\%) & $71(56.8)$ & $30(61.2)$ & $41(53.9)$ & 0.423 \\
\hline Education level, years, mean (SD) & $9.5(6.1)$ & $10.5(6.1)$ & $8.0(5.7)$ & 0.016 \\
\hline $\mathrm{BMI}, \mathrm{kg} / \mathrm{m}^{2}$ mean (SD) & $25.1(3.9)$ & $24.8(3.7)$ & $25.3(4.0)$ & 0.508 \\
\hline Family history of Dementia, $\mathrm{n}(\%)$ & $10(8.0)$ & $5(10.2)$ & $5(6.6)$ & 0.466 \\
\hline Smoking, n (\%) & $41(32.8)$ & $16(32.7)$ & $25(32.9)$ & 0.978 \\
\hline History of alcohol, n (\%) & $24(19.2)$ & $8(16.3)$ & $16(21.1)$ & 0.513 \\
\hline Hypertension, n (\%) & $90(72.6)$ & $36(73.5)$ & $54(72)$ & 0.858 \\
\hline Diabetes, n (\%) & $47(37.6)$ & $12(24.5)$ & $35(46.1)$ & 0.015 \\
\hline Background head injury, n (\%) & $13(10.4)$ & $5(10.2)$ & $8(10.5)$ & 0.954 \\
\hline History of Stroke, n (\%) & $25(20.0)$ & $4(8.2)$ & $21(27.6)$ & 0.008 \\
\hline Dyslipidemia, n (\%) & $80(64.0)$ & $29(59.2)$ & $51(67.1)$ & 0.368 \\
\hline Hypothyroidism, n (\%) & $37(29.6)$ & $16(32.7)$ & $21(27.6)$ & 0.548 \\
\hline Cardiovascular disease, n (\%) & $24(19.4)$ & $6(12.5)$ & $18(23.7)$ & 0.125 \\
\hline Atrial fibrillation, $\mathrm{n}(\%)$ & $11(8.8)$ & $3(6.1)$ & $8(10.5)$ & 0.396 \\
\hline Depression, n (\%) & $49(39.2)$ & $18(36.7)$ & $31(40.8)$ & 0.650 \\
\hline Cholesterol, mg/dl mean (SD) & $179.1(38.6)$ & $184.6(37.2)$ & $175.5(39.2)$ & 0.211 \\
\hline Triglycerides, mg/dl mean (SD) & $133.1(54.0)$ & $136.1(57.5)$ & $131.2(51.9)$ & 0.623 \\
\hline MMSE, score mean (SD) & $23.8(4.7)$ & $26.7(3.07)$ & $21.91(4.6)$ & $<0.001$ \\
\hline Clock Test score, mean (SD) & $3.7(2.7)$ & $2.9(2.4)$ & $4.2(2.8)$ & 0.014 \\
\hline Instant recall, \# words, mean (SD) & $4.0(0.9)$ & $4.4(0.7)$ & $3.8(1.0)$ & 0.002 \\
\hline Memory deferred \# words, mean (SD) & $3.0(1.7)$ & $3.8(1.3)$ & $2.5(1.8)$ & 0.002 \\
\hline Fluent phonological abnormal, \# words, mean (SD) & $8.8(4.7)$ & $9.7(4.4)$ & $7.7(4.9)$ & 0.195 \\
\hline Semantic fluency abnormal, \# words, mean (SD) & $12.9(6.4)$ & $16.1(6.6)$ & $9.1(3.6)$ & 0.005 \\
\hline FAB total score, mean (SD) & $11.8(3.8)$ & $12.4(3.9)$ & $11.3(3.6)$ & 0.189 \\
\hline
\end{tabular}

Significance was set at 0.05 .

FAB: Frontal Assessment Battery; MCl: mild cognitive impairment; MMSE: Mini-Mental State Examination; SD: Standard Deviation.

The univariate Cox regression analysis showed that diabetes $(p=0.047)$ and stroke $(p=0.014)$ were associated with progression from $\mathrm{MCl}$ to dementia. Age $(p<0.001)$, years of education $(p=0.044)$, and cognitive decline (MMSE) $(p<0.001)$ were associated with the odds of incident dementia (Table 2).

Finally, multivariate Cox regression analysis did not change the direction of associations. Older age increased the risk of conversion to dementia (HR: $4.95 ; 95 \% \mathrm{Cl}$ : 1.96-12.46; $\mathrm{p}<0.001$ ). Six years or less of education (HR: $5.81 ; 95 \% \mathrm{Cl}: 1.90-7.78 ; \mathrm{p}=0.002$ ), a history of stroke (HR: 3.92; $95 \% \mathrm{Cl}: 1.37-11.16 ; \mathrm{p}=0.010$ ), and cognitive decline (HR: $1.31 ; 95 \% \mathrm{Cl}: 1.18-1.45$; $\mathrm{p}<0.000$ ) remained statistically significantly associated with progression to dementia (Table 3, Fig. 1).
The Kaplan-Meier curve with the following covariates: age, education, history of stroke, and cognitive decline. For the model, Cox regression coefficients were estimated using progression to dementia. Patients were classified into two groups according to their risk scores (predicted values derived from multivariate Cox regressions), with cutoff points at the median risk score in each model. We could predict the median conversion to dementia and the 3.5-year survival probabilities for patients with progressive or stable $\mathrm{MCl}$.

\section{DISCUSSION}

In this study, 125 individuals with a baseline diagnosis of $\mathrm{MCl}$ were evaluated by clinical and neuropsychological 
Table 2. Hazard ratios from the Cox model for conversion to dementia

\begin{tabular}{|c|c|c|c|c|}
\hline Covariate & Coefficient (bi) & HR & $(95 \% \mathrm{Cl})$ & $p$ value \\
\hline \multicolumn{5}{|l|}{$\overline{\text { Age, } n(\%)}$} \\
\hline $65-74$ years & - & 1.00 & - & - \\
\hline $75-84$ years & 3.12 & 3.308 & $(1.559-7.019)$ & 0.002 \\
\hline$\geq 85$ years & 4.60 & 7.933 & $(3.280-19.188)$ & $<0.001$ \\
\hline \multicolumn{5}{|l|}{ Education } \\
\hline None & - & 1.00 & - & - \\
\hline$\leq 6$ years & 0.38 & 1.211 & $(0.456-3.214)$ & 0.044 \\
\hline$>6$ years & 2.01 & 0.545 & $(0.301-0.985)$ & 0.070 \\
\hline Diabetes & 1.99 & 1.937 & $(1.009-3.719)$ & 0.047 \\
\hline History of stroke & 2.45 & 3.610 & $(1.294-10.07)$ & 0.014 \\
\hline MMSE, score & 4.70 & 1.242 & $(1.135-1.359)$ & $<0.001$ \\
\hline Clock drawing test, score & -2.04 & 0.872 & $(0.765-0.994)$ & 0.041 \\
\hline Instant recall, \# words & 2.62 & 1.598 & $(1.125-2.271)$ & 0.009 \\
\hline Memory deferred \# words & 3.00 & 1.351 & $(1.109-1.645)$ & 0.003 \\
\hline Semantic fluency abnormal, \# words & 2.60 & 1.085 & $(1.020-1.154)$ & 0.009 \\
\hline
\end{tabular}

Mild cognitive impairment diagnosis (yes is reference)

Age (65-74 years is the reference)

Education (no. years is the reference)

Diabetes and history of stroke presence is the reference

$\mathrm{HR}$ : hazard rate; $\mathrm{Cl}$ : confidence interval; $\mathrm{p}$ value $<0.05$. MMSE $=$ Mini-Mental State Examination.

Table 3. Hazard ratios for predictor of dementia

\begin{tabular}{|c|c|c|c|c|}
\hline Predictors & $\beta$ & HR & $(95 \% \mathrm{Cl})$ & $p$ value \\
\hline \multicolumn{5}{|l|}{ Age, n (\%) } \\
\hline $65-74$ years & - & 1.00 & - & - \\
\hline $75-84$ years & 1.51 & 1.80 & $(0.83-3.90)$ & 0.131 \\
\hline$\geq 85$ years & 3.40 & 4.95 & $(1.96-12.46)$ & 0.001 \\
\hline \multicolumn{5}{|l|}{ Education } \\
\hline None & - & 1.00 & - & - \\
\hline$\leq 6$ years & 3.09 & 5.81 & $(1.90-7.78)$ & 0.002 \\
\hline$>6$ years & -3.35 & 0.34 & $(1.18-0.64)$ & 0.001 \\
\hline History of Stroke & 5.35 & 1.31 & $(1.181-1.452)$ & $<0.000$ \\
\hline
\end{tabular}

HR: hazard ratio; $\mathrm{Cl}$ : confidence interval; $\mathrm{p}$ value $<0.05$.

MMSE: Mini-Mental State Examination.

procedures after an average follow-up time of 3.5 years; $76 / 125$ (61\%) progressed to dementia. As expected, advanced age, low education level, cognitive decline, and a history of stroke were independent predictors of dementia risk. Previous reports describe an annual conversion rate ranging from 8.3 to $33.6 \%$, and a reversion rate that varies from 2.0 to $53.0 \%{ }^{25,26}$. The Italian Longitudinal Study on Aging found a progression rate of 3.8 (95\% Cl: 2.3-6.2) per 100 person-years among 139 individuals (65-84 years old) with baseline $\mathrm{MCl}$, after 3.5-year follow-up ${ }^{27}$. Our study was carried out in a referral hospital, which could explain the particular characteristics of the studied subjects such as the burden of disease and the high proportion of progression to dementia. Only a few Mexican studies have included clinical and neuropsychological evaluations to identify different cognitive profiles in early stages of dementia. In Mexico, $\mathrm{MCl}$ has been poorly studied and its prevalence and incidence is varied, even in epidemiological reports ${ }^{28}$. A cross-sectional epidemiological study, called 10/66 Dementia Research Group, that included a large sample of middle- and low-income subjects, was carried out in Cuba, Dominican Republic, Mexico, Peru, Puerto Rico, Venezuela, China, and India with 15,376 Individuals aged $65+$ without dementia. The study investigated the prevalence of $\mathrm{MCl}$, according to Mayo Clinic criteria, and its association with sociodemographic conditions. They show a large variability in the prevalence of $\mathrm{MCl}$ (from 
Figure 1. Cumulative hazards according to the status of stable $\mathrm{MCl}$ and progressive $\mathrm{MCl}(\mathrm{p}<0.000$; log-rank test). These data are further supported by the Cox regression analysis presented in table of univariate and multivariate analysis of prognostic variables by Cox regression analysis. $\mathrm{MCl}$ : mild cognitive impairment.

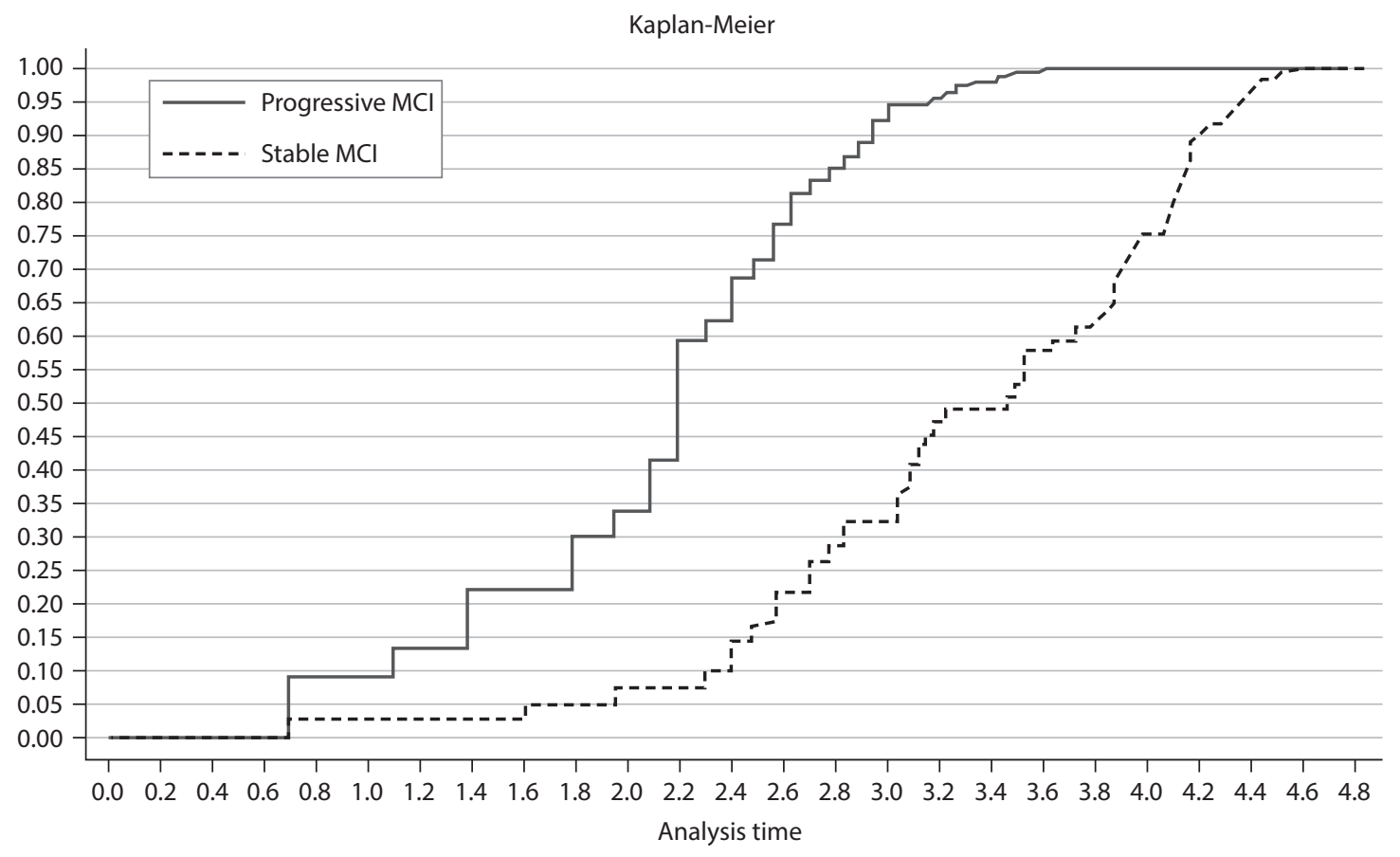

$0.8 \%$ in China to $4.3 \%$ in India). But when Latin American countries were compared, the results were more homogenous. In Mexico, the prevalence of $\mathrm{MCl}$ was $2.8 \%$, with a modest association with male sex and less physical activity, but not with age or poor education ${ }^{29}$.

On the other hand, previous community-based studies also reported predictors of $\mathrm{MCI}$ progression: older age, less years of schooling, depression, history of diabetes or stroke, African American and Hispanic ethnicity, and lower baseline MMSE score ${ }^{30}$. Recently, the communitybased Shanghai Aging Study investigated the progression of cognitive decline in Chinese elderly ${ }^{31}$. They found that the conversion rate to dementia was 6.0 per 100 personyears, while the reversion rate to cognitive normality was 7.8 per 100 person-years. Multiple-domain amnestic $\mathrm{MCl}$ represented the highest risk for dementia (conversion rate: 14.2 per 100 person-years). Older age (HR: 1.09), apolipoprotein E (APOE ع4; HR: 2.15), and low MMSE score (HR: 1.18) were predictors for dementia. In that study, age was considered the main risk factor for developing dementia. Evidence from autopsy, epidemiological, and cohort studies show that advanced age is the strongest risk factor for the development of Alzheimer's disease related to pathophysiological abnormalities and the ultimate development of symptomatic Alzheimer's disease ${ }^{31}$. Even so, there is a significant heterogeneity between individuals in the age-specific prevalence of Alzheimer's-related pathology: some individuals appear relatively spared from developing the pathognomonic Alzheimer's brain lesions even in old age ${ }^{32}$.

Recognizing potentially modifiable factors has always been a challenge in dementia care. In early forms of cognitive impairment such as $\mathrm{MCl}$, this could represent an opportunity to prevent or delay progression to dementia. Recently, an observational study in 638 subjects reported that vascular factors, such as hypertension, hypercholesterolemia, diabetes, and cerebrovascular disease, increased the risk of incident Alzheimer's dementia after adjusting for potential confounding factors (OR: 2.03; $95 \% \mathrm{Cl}: 1.33-3.14)^{33}$. It has been proven that stroke (clinical and subclinical) is associated with progressive dementia, with a previous study showing that $20 \%$ of 653 patients with cerebrovascular disease developed dementia ${ }^{34}$. Moreover, it has been demonstrated that $21 \%$ of subjects with stroke developed dementia ${ }^{35}$. The association between stroke and cognitive 
impairment depends on several factors, such as lesion size and location, extent of damage to the white matter, and the region involved ${ }^{35}$. Our study showed that, of all the vascular risk factors related to progression, a history of stroke was the most strongly associated.

This study contributes to a better understanding of cognitive characteristics of a small sample of subjects in a memory clinic and, through monitoring, the understanding of factors that have been associated with conversion to dementia. We were able to achieve these results through a selection and exhaustive characterization of a sample, with properly documented risk factors to ensure their representative association. Given the nature of the study, the main limitation was the design and the fact that 50 subjects ( $28.7 \%$ ) were excluded from the follow-up, which could have affected the interpretation of our results. Furthermore, the information was obtained from clinical records, which could limit the identification of potential factors associated with the progression to dementia.

More longitudinal studies are needed in Mexico, where not yet clearly known psychosocial, medical, genetic, or biological factors may contribute to the development of $\mathrm{MCl}$. The importance of the diagnosis of early forms of cognitive impairment should not be minimized. The course of $\mathrm{MCl}$ should be closely monitored and intervened in an attempt to prevent progression to dementia.

\section{REFERENCES}

1. Petersen RC, Smith GE, Waring SC, et al. Mild cognitive impairment: clinical characterization and outcome. Arch Neurol. 1999; 56:303-8

2. Jak AJ, Preis SR, Beiser AS, et al. Neuropsychological criteria for mild cognitive impairment and dementia risk in the Framingham Heart Study. J Int Neuropsychol Soc. 2016;22:937-943.

3. Petersen RC, Rosebud O, Roberts RO, et al. Mild cognitive impairment: ten years later. Arch Neurol. 2009;66:1447-55.

4. Prince M, Bryce R, Albanese E, Wimo A, Ribeiro W, Ferri CP. The global prevalence of dementia: a systematic review and metaanalysis. Alzheimers Dement. 2014;9:63-75.

5. Roberts R, Knopman DS. Classification and epidemiology of mild cognitive impairment. Clin Ger Med. 2013;29:753-72.

6. Koepsell TD, Monsell SE. Reversion from mild cognitive impairment to normal or near-normal cognition: risk factors and prognosis. Neurology. 2012;79:1591-8.

7. Campbell NL, Unverzagt F, LaMantia MA, Khan BA, Boustani MA. Risk factors for the progression of mild cognitive impairment to dementia. Clin Ger Med. 2013;29:873-93.

8. Prince M, Albanese E, Guerchet M, Prina M. World Alzheimer's Report 2014: Dementia and risk reduction. An analysis of protective and modifiable factors. Public health priority. [e-journal] 2014. Available at: www.alz.co.uk/research/ [Accessed November 10, 2014]

9. Folstein MF, Folstein SE, McHugh PR. "Mini-Mental State" a practical method for grading the cognitive state of patients for the clinician. J Psychiatric Res. 1975;12:189-98.
10. Morris J. The clinical dementia rating (CDR): Current version and scoring rules. Neurology. 1993;43:2412-14.

11. Katz S, Ford AB, Moskowitz RW, et al. Studies of illness in the aged. The index of ADL: A standardized measure of biological and psychological function. JAMA. 1963;185:914-19

12. Lawton MP, Brody EM. Assessment of older people: Self-maintaining and instrumental activities of daily living. Gerontologist. 1969;9:179-86.

13. Petersen RC. Clinical practice. Mild cognitive impairment. N Engl Med. 2011;364:2227-2234

14. Dubois B, Touchon J, Portet F, Ousset PJ, Vellas B, Michel B. The 5 words': A simple and sensitive test for the diagnosis of Alzheimer's disease. Presse Med. 2002;31:1696-9.

15. Canning SJ, Leach L, Stuss D, Ngo L, Black SE. Diagnostic utility of abbreviated fluency measures in Alzheimer disease and vascular dementia. Neurology. 2004;62:556-62.

16. Dubois B, Slachevsky A, Litvan I, Pillon B. The FAB: A frontal assessment battery at bedside. Neurology. 2000;55:1621-6.

17. Shulman KI. Clock-drawing: Is it the ideal cognitive screening test? Int J Geriatr Psychiatry. 2000;15:548-61.

18. American Psychiatric Association. Diagnostic and Statistical Manual of Mental Disorders, Fourth Edition Text Revision (DSM-IV-TR) Barcelona: Masson. 2002.

19. Pohjasvaara T, Mantyla R, Ylikoski R, Kaste M, Erkinjuntti T. Comparison of different clinical criteria (DSM-III, ADDTC, ICD10, NINDS-AIREN, DSM-IV) for the diagnosis of vascular dementia. National Institute of Neurological Disorders and StrokeAssociation Internationale pour la Recherche et l' Enseignement en Neurosciences. Stroke. 2000;31:2952-7.

20. Neary D, Snowden JS, Gustafson L, et al. Frontotemporal lobar degeneration: a consensus on clinical diagnostic criteria. Neurology. 1998;51:1546-54.

21. McKeith I, Dickson DW, Lowe J, et al. Diagnosis and management of dementia with Lewy bodies: third report of the DLB Consortium. Neurology. 2005;65:1863-72.

22. Roman GC, Tatemichi TK, Erkinjuntti T, et al. Vascular dementia: diagnostic criteria for research studies. Report of the NINDSAIREN International Workshop. Neurology. 1993;43:250-60.

23. O'Connor PG, Schottenfeld RS. Patients with alcohol problems. N Engl J Med. 1998;338:592-602.

24. Yesavage JA, Brink TL, Rose TL, et al. Development and validation of a geriatric depression screening scale: a preliminary report. J Psychiat Res. 1982;17:34-7.

25. Katz Mj, Lipton RB, Hall CB, et al. Age and sex specific prevalence and incidence of mild cognitive impairment, dementia and Alzheimer's dementia in blacks and whites: A report from The Einstein Aging Study. Alzheimer Dis Assoc Disord. 2012;26:335-43.

26. Vos SJ, Xiong C, Visser PJ, et al. Preclinical Alzheimer's disease and its outcome: a longitudinal cohort study. Lancet Neurol. 2013;12:957-65

27. Solfrizzi V, Panza F, Colacicco AM, et al. Vascular risk factors, incidence of $\mathrm{MCl}$, and rates of progression to dementia. Neurology. 2004;63:1882-91.

28. Mejia-Aranjo S, Gutiérrez-Robledo LM. Prevalence and incidence rates of dementia and cognitive impairment no dementia in the Mexican population: data from the Mexican Health and Aging Study. J Aging Health. 2011;23:1050-74.

29. Sosa AL, Albanese E, Stephan BC, et al. Prevalence, distribution, and impact of mild cognitive impairment in Latin America, China and India: A 10/66 Population-Based Study. PLoS Med. 2012;9. e1001170.

30. Cooper C, Sommerlad A, Lyketsos CG, et al. Modifiable predictors of dementia in mild cognitive impairment: a systematic review and meta-analysis. Am J Psychiatry. 2015;172:323-34.

31. Ding D, Zhao O, Guo Q, et al. Progression and predictors of mild cognitive impairment in Chinese elderly: A prospective follow-up in the Shanghai Aging Study. Alzheimers Dement (Amst). 2016; 4:28-36.

32. Inselberg R, Massarwa M, Schechtman E, Strugatsky R, Farrer LA, Friedland RP. Estimating the risk for conversion from mild cognitive impairment to Alzheimer's disease in an elderly Arab community. J Alzheimers Dis. 2015;45:865-71.

33. Li J, Wanj YJ, Zhang M, et al. Vascular risk factors promote conversion from mild cognitive impairment to Alzheimer disease. Neurology. 2011;76:1485-91.

34. Bejot Y, Aboa-Eboulé C, Durier J, et al. Prevalence of early dementia after first-ever stroke: a 24-year population based study. Stroke. 2011;42:607-12.

35. Khedr EM, Hamed SA, El-Shereef HK, et al. Cognitive impairment after cerebrovascular stroke: relationship to vascular risk factors. Neuropsychiatr Dis Treat. 2009;5:103-16. 